\title{
REVISÃO SISTEMÁTICA SOBRE O USO DE EFLUENTES NA AGRICULTURA
}

\author{
Rafael Ludwig
}

Fernando Ferrari Putti ${ }^{2}$

\section{Ramilos Rodrigues de Brito ${ }^{3}$}

RESUMO: A crescente demanda de alimentos impulsiona a busca por aumento da produtividade agrícola. Para tanto, é fundamental que as plantas expressem o seu máximo potencial produtivo, o qual está relacionado a disponibilidade de água e nutrientes em níveis adequados. Com a crescente demanda de água para irrigação há necessidade de desenvolver alternativas para suprir essa necessidade. Estudos apontam o reuso da água como alternativa para suprir essa crescente demanda hídrica na irrigação. Desta forma, este estudo buscou mapear e discutir as produções científicas a cerca do reuso de efluentes na agricultura brasileira. Realizou-se uma revisão sistemática nas bases de dados do SCIELO, com objetivo de identificar, descrever e analisar o que se tem produzido no campo científico a cerca deste tema. Utilizou-se para busca as combinações dos descritores: irrigação e reuso; efluente e agricultura; irrigação e efluente; e reuso e agricultura. Encontrou-se 99 artigos, publicados a partir de 2000. Após a exclusão dos estudos repetidos e dos que não apresentavam relevância ao tema desta pesquisa restaram 27 artigos, os quais foram agrupados em 5 temas, sendo eles: Sistemas e técnicas de irrigação; Desenvolvimento e qualidade

\footnotetext{
${ }^{1}$ Engenheiro Agrícola, Doutorando em Agronomia - Irrigação e Drenagem, Faculdade de Ciências Agronômicas UNESP - Botucatu, rafaludwig@yahoo.com.br.

${ }^{2}$ Mestrando em Irrigação e Drenagem, UNESP/FCA - SP.

${ }^{3}$ Eng. Agrônomo, Mestrando em Irrigação e Drenagem, UNESP/FCA - SP
} 
das culturas; Estado nutricional; Impacto das águas residuária; Nutrientes com água de reuso. Esse estudo permitiu perceber o crescente interesse da comunidade científica sobre os efeitos do reuso de efluentes para agricultura, tornando possível concluir que a utilização desses é uma alternativa viável ao problema de escassez de água. É ainda fonte de nutrientes para as plantas e consequentemente aumentando a produtividade das culturas irrigadas.

Palavras-chave: Reuso na irrigação. Controle ambiental. Águas residuária.

\section{INTRODUÇÃO}

O crescente aumento na necessidade de alimentos exige que tenhamos uma produção cada vez maior. Este aumento de produção pode ser alcançado fazendo com que as plantas expressem o seu máximo potencial produtivo, significando que a água e os nutrientes no solo deverão estar em níveis adequados.

Em regiões nas quais as precipitações não atendem a demanda hídrica pode-se utilizar a irrigação (VIEIRA, 1989). Por outro, lado sabe-se que a disponibilidade de água potável está cada vez mais escassa, ficando à irrigação na ponta da demanda de água no Brasil, com 15,96 km $\mathrm{ano}^{-1}$, aproximadamente duas vezes maior que a industrial que é de $7,8 \mathrm{~km}^{3} \mathrm{ano}^{-1}$. Entre os estados com maior necessidade é o Rio Grande do Sul $6,32 \mathrm{~km}^{3}$ ano $\left.{ }^{-1}\right)$, seguido por São Paulo $\left(1,81 \mathrm{~km}^{3} \mathrm{ano}^{-1}\right)$ (TUNDISI, 2005). A maior demanda de recursos hídricos pela região sul foi associada por Silvestre (2003) à grande área de irrigação, representando $41,6 \%$ do total da área irrigada no país.

Muitos estudos apontam o reuso da água como alternativa para suprir essa crescente demanda hídrica na irrigação. Para Florencio et al. (2006), este oferece oportunidades de natureza econômica, ambiental e social, podendo constituir-se em uma necessidade nas situações de escassez. Nobre, Gheyi et al. (2010), destacam que o uso da água residuária na agricultura visa promover a sustentabilidade da agricultura irrigada, pois economiza as águas superficiais não poluídas, mantendo a qualidade ambiental e servindo como fonte nutritiva às plantas.

No entanto, a utilização da água residuárias deve atender a regulamentação do país, a qual está em pleno curso no Brasil através da resolução do CONAMA número 357 
de 2005 (BRASIL, 2005a), que estabelece os padrões para o lançamento de efluentes. Segundo a resolução número 54 de 2005 (BRASIL, 2005b) o reúso é considerado parte integrante da política nacional de gestão de recursos hídricos.

A reutilização da água residuárias na agricultura além de suprir a demanda hídrica, fornece aporte de nutrientes, sendo ainda, uma forma inteligente de destino dos efluentes.

Nesse panorama, o presente estudo trata-se de uma revisão sistemática que buscou encontrar na literatura publicações científicas a respeito da reutilização de efluentes.

\section{MÉTODO}

Para conhecer a situação atual do reuso de efluentes na agricultura Brasileira realizou-se uma revisão sistemática nas bases de dados do SCIELO, com objetivo de identificar, descrever e analisar o que se tem produzido no campo científico a cerca deste tema.

Utilizou-se para busca as combinações de descritores: irrigação e reuso; efluente e agricultura; irrigação e efluente; e reuso e agricultura. Foram selecionadas publicações em português que permitissem acesso aos textos completos. Optou-se associar as expressões reuso e efluente com irrigação e agricultura, pois estes são os temas que serão avaliados.

Durante a pesquisa foram encontrados 99 artigos, publicados a partir de 2000, quando esse tema passa a ser abordado nas publicações nacionais. Após a exclusão dos estudos repetidos e dos que não apresentavam relevância ao tema desta pesquisa restaram 27 artigos, os quais foram agrupados em 5 temas, sendo eles: Sistemas e técnicas de irrigação; Desenvolvimento e qualidade das culturas; Estado nutricional; Impacto das águas residuária; Nutrientes com água de reuso.

\section{RESULTADOS}




\section{Periádica Eletránica

Ao analisar os resultados obtidos percebe-se que a temática do reuso teve um crescente aumento nos últimos anos principalmente após 2005. Destaque maior para o ano de 2012, no qual até o momento consta com 7 publicações o que representa $26 \%$ do total analisado, número bastante superior aos anos anteriores (Tabela 1 e Figura 1).

Tabela 1 - Organização dos estudos por temas

\begin{tabular}{lccccccccccc}
\hline \multicolumn{1}{c}{ Temas } & 2000 & 2003 & 2005 & 2006 & 2007 & 2008 & 2009 & 2010 & 2011 & 2012 & Total \\
\hline $\begin{array}{l}\text { Sistemas e técnicas } \\
\text { de irrigação }\end{array}$ & - & & 2 & - & 1 & 1 & 1 & - & 1 & 1 & 7 \\
$\begin{array}{l}\text { Desenvolvimento e } \\
\text { qualidade das } \\
\text { culturas }\end{array}$ & - & 1 & - & 1 & 2 & - & - & 3 & 1 & 3 & 11 \\
$\begin{array}{l}\text { Estado nutricional } \\
\begin{array}{l}\text { Impacto das águas } \\
\text { residuárias }\end{array}\end{array}$ & - & - & - & - & - & 1 & - & - & - & - & 1 \\
$\begin{array}{l}\text { Nutrientes com água } \\
\text { de reuso }\end{array}$ & - & - & - & - & - & - & 1 & - & - & 2 & 3 \\
$\begin{array}{l}\text { Produções } \\
\text { Publicadas por ano }\end{array}$ & $\mathbf{1}$ & $\mathbf{1}$ & $\mathbf{2}$ & $\mathbf{1}$ & $\mathbf{3}$ & $\mathbf{3}$ & $\mathbf{3}$ & $\mathbf{4}$ & $\mathbf{2}$ & $\mathbf{7}$ & $\mathbf{2 7}$ \\
\hline
\end{tabular}

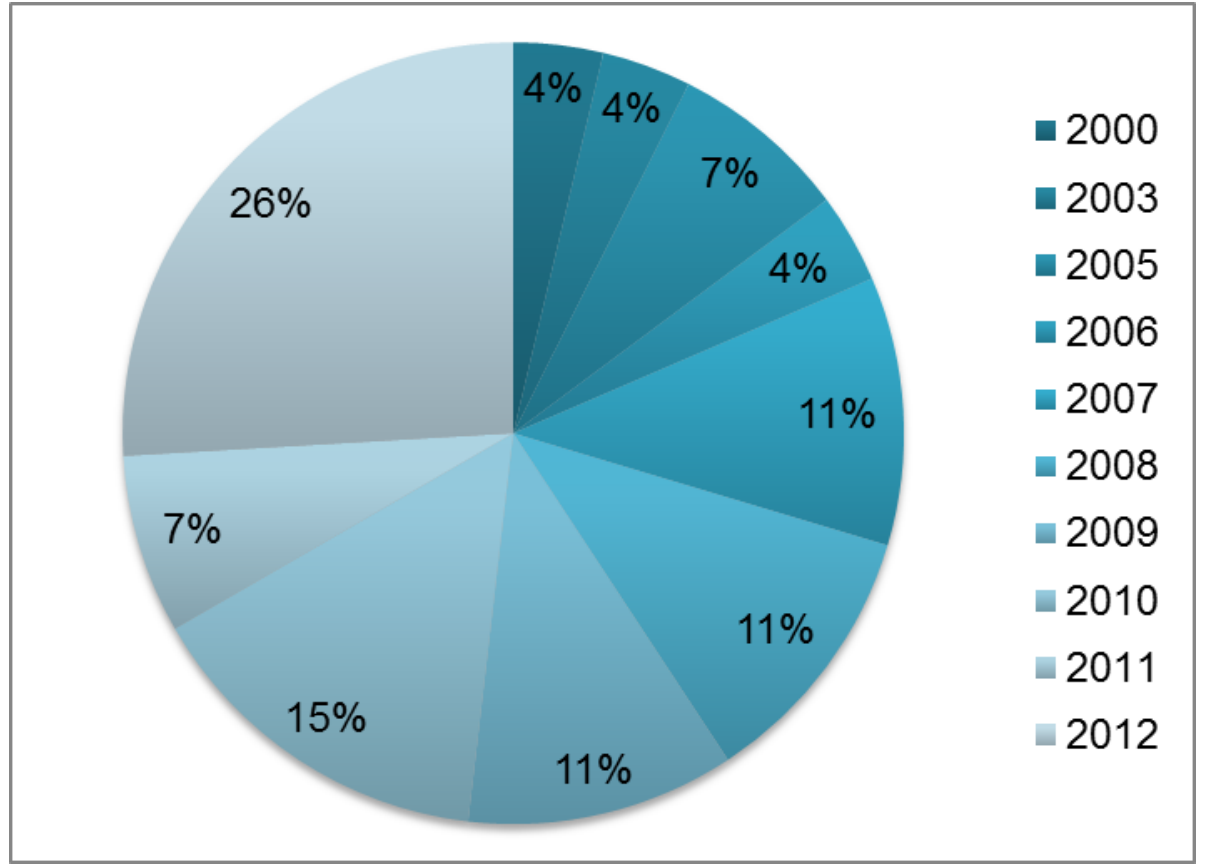

Figura 1 - Produções Publicadas por ano 
Observa-se na Tabela 1 e Figura 2 que o tema desenvolvimento e qualidade das culturas apresentou o maior numero de publicações totalizando $41 \%$ seguido de sistemas e técnicas de irrigação o qual totalizou $26 \%$.

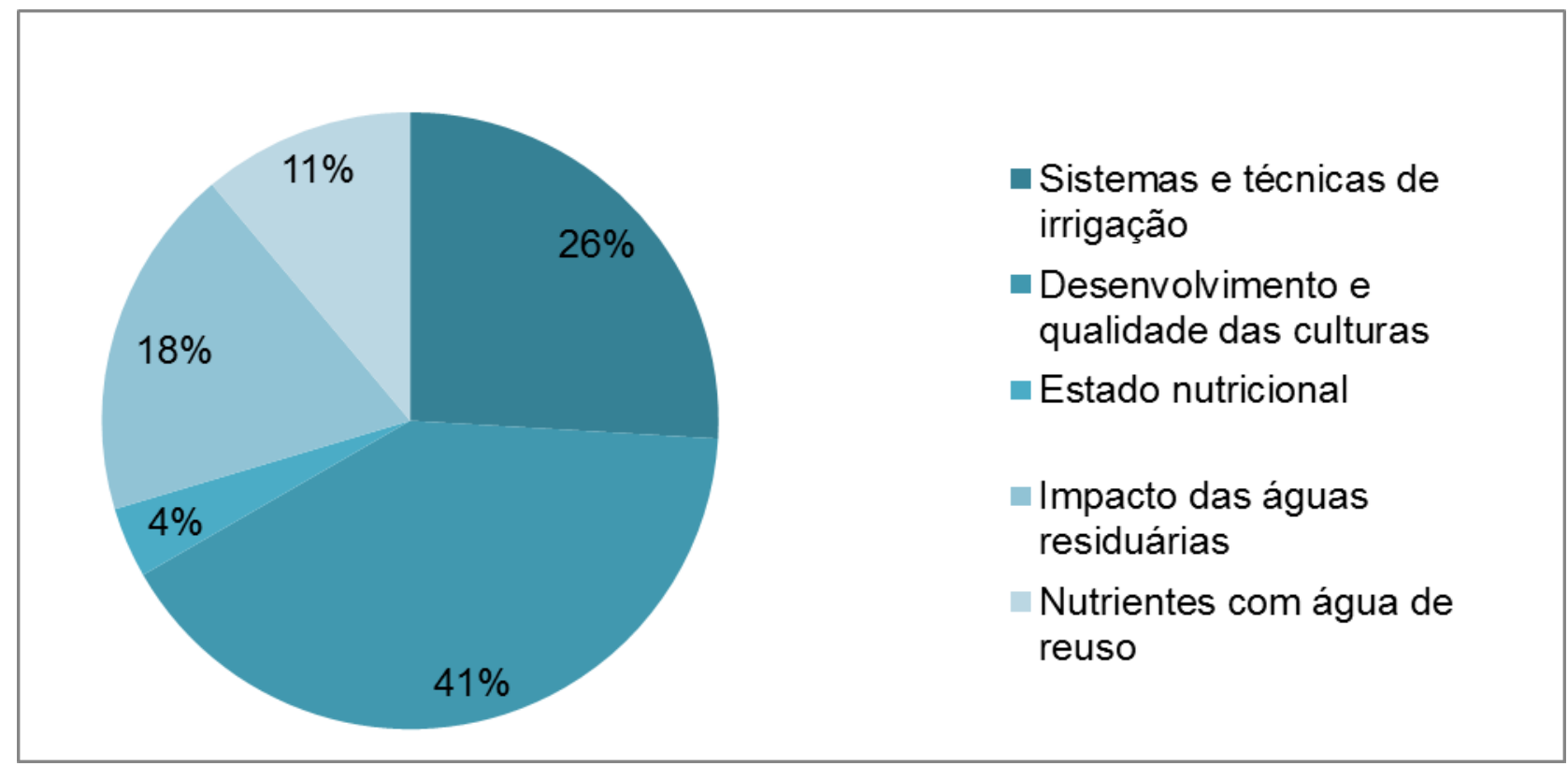

Figura 2 - Temas estudados.

Na temática do desenvolvimento e qualidade das culturas, as abordagens foram relacionadas ao efeito da reutilização da água residuária na produtividade das culturas, dentre as técnicas de cultivo tem-se o cultivo hidropônico e o cultivo em solo. Em relação ao efluente utilizado $56 \%$ dos trabalhos utilizou o esgoto doméstico tratado.

Dentre os trabalhos que abordaram sistemas e técnicas de irrigação, os estudos foram relacionados as técnicas de irrigação, perda de carga nas tubulações, sistemas de filtragem, entupimento na irrigação por gotejamento e sistemas de tratamento dos efluentes. Esta foi a única temática que não utilizou nenhuma cultura para analise.

Dos 27 trabalhos analisados $70 \%$ trabalharam com o comportamento das plantas. A cultura da alface foi a que apareceu mais vezes nos estudos com um total de $21 \%$. 


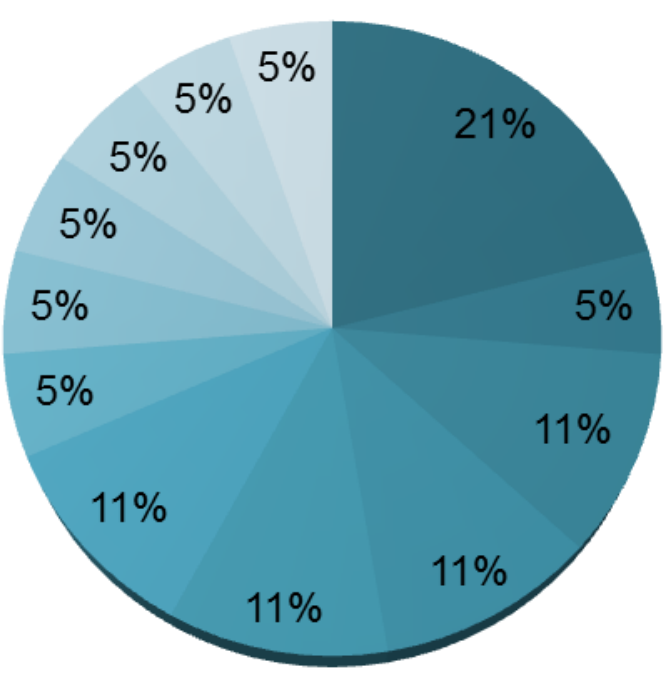

- Alface

- Algodão

- Café

- Cana-de-açúcar

- Girassol

- Mamoeira

Melancia

- Melão

Pepino

Pimentão

Pinhão-manso

Plantas ornamentais

Figura 3 - Plantas estudadas

\section{DISCUSSÃO}

A busca por soluções para o constante aumento da população, consequentemente aumento da demanda por água e alimentos, apontam para o aproveitamento dos efluentes das estações de tratamento de esgoto na agricultura (Cararo e Botrel, 2007). Isto é comprovado ao analisar os trabalhos, os quais apontam essa como uma alternativa viável a encases de água, além de auxiliar na adubação, reduzindo os custos para o produtor.

Sousa Neto, Andrade Filho et al. (2012) obtiveram na irrigação do algodoeiro com água residuária influencia significativa no crescimento deste, em relação ao índice de velocidade de emergência, à percentagem de germinação à altura de plantas, ao diâmetro caulinar e número de folhas e à área foliar e massa seca de parte aérea. Destaca ainda que o aumento se deu com o acréscimo da proporção de uso do efluente doméstico.

$\mathrm{Na}$ mesma linha Medeiros, Soares et al. (2008) perceberam que a adoção da água residuária proporcionou melhorias no estado nutricional do cafeeiro. A produção de matéria fresca e produção das culturas também ganham destaque em outros trabalhos que adotaram a utilização de efluente. 
Azevedo e Oliveira (2005), estudando a cultura do pepino obtiveram produção de matéria fresca com uso de efluente de esgoto $41 \%$ superior em relação ao tratamento testemunha. $O$ autor ainda destaca o significado desse valor, o qual demonstra que 0 efluente pode ser utilizado para fornecer nutrientes e consequentemente aumentar a produtividade. Destacando ainda que a fertirrigação com efluente doméstico tratado pode substituir a adubação convencional do algodoeiro Sousa Neto, Andrade Filho et al. (2012).

Observou-se que a cultura da alface foi a mais utilizada nos experimentos, o que pode ser explicado pelo fato de ser uma hortaliça de ciclo curto, com grande importância econômica (Sandri, Matsura et al., 2007). Porém cabe ressaltar que a utilização dos efluentes na prática da fertirrigação pode tornar necessário a sua desinfecção, dependendo da cultura e o sistema de irrigação utilizado (Paterniani, Silva et al., 2011).

Com relação ao sistema de irrigação adotado nos estudos o que apresentou maior desempenho foi o sistema por gotejamento. Cararo e Botrel (2007) classificam esse como o mais seguro para reuso de efluente. Sandri, Matsura et al. (2007), também obteve os melhores resultados com a utilização desse sistema tanto no desenvolvimento da alface, como na classificação comercial e na eficiência no uso da água.

Outro ponto que foi levantados nos estudos foi a necessidade de atentar para os efeitos causados pela água residuária no solo, pois essa pode acarretar mudanças no comportamento físico-químico do solo (Varallo, Souza et al., 2012). Oliveira, Campelo et al. (2000), evidenciaram que aumentos na concentração de sólidos totais nas águas de reuso de suinocultura reduzem a capacidade de infiltração do solo. Igualmente para a elevação do teor do íon sódio no solo, motivo pelo qual Varallo, Carvalho et al. (2010) destacam que a utilização de água de reuso deve se dar de forma racional.

Além disso, deve-se atentar para a concentração de partículas nas águas de reuso para irrigação, as quais poderão causar entupimentos no sistema e consequentemente reduzir a uniformidade. O entupimento em sistema de irrigação por gotejamento consiste em um fator restritivo a sua utilização (Cararo e Botrel, 2007). Mas uma alternativa para amenizar isso é a utilização de sistemas de filtragem. A associação de sistemas de pré-filtração e filtração lenta mostraram-se eficientes na redução das concentrações de sólidos suspensos, turbidez, cor aparente e DQO, como polimento de esgotos domésticos previamente tratados (Paterniani, Silva et al., 2011). Estes autores 
também avaliaram o uso de carvão ativado granular, o qual em combinação com areia proporcionou ao filtro lento maior eficiência na remoção de sólidos suspensos, cor, turbidez, coliformes totais e E. coli, sem com isso aumentar a perda de carga inicial.

Barreto e Campos (2009) verificaram que a perda de carga foi influenciada pela concentração de sólidos contidos na água residuária, acrescentando 30,77\% na adutora, $13,59 \%$ na turbina e $22,02 \%$ na mangueira. Por outro lado, a uniformidade de distribuição e o raio de alcance do aspersor não foram influenciados pela concentração de sólidos, os quais, analisando o raio de alcance do aspersor, ficaram mais concentrados nos coletores mais afastados do aspersor.

Estas abordagens mostram que a utilização do efluente é uma alternativa viável frente à escassez de água, sendo necessário atentar para concentração de sólidos, qualidade sanitária e forma de aplicação, para que não se altere a qualidade dos produtos. Além de controlar o volume aplicado para evitar impactos no solo.

\section{CONCLUSÕES}

Esse estudo permitiu perceber o crescente interesse da comunidade científica nos efeitos do reuso de efluentes para agricultura. E tornou possível concluir que a utilização desses é uma alternativa viável ao problema de escassez de água, tornando-se ainda fonte de nutrientes para as plantas e consequentemente aumentando a produtividade das culturas irrigadas.

Deve-se analisar a escolha do sistema de irrigação, optando por aquele que cause a menor contaminação nas plantas, principalmente quando essas são consumidas in natura. Desta forma, destaca-se a irrigação por gotejamento a utilização de filtros e analise das características físicas, químicas e biológicas dessas águas. 


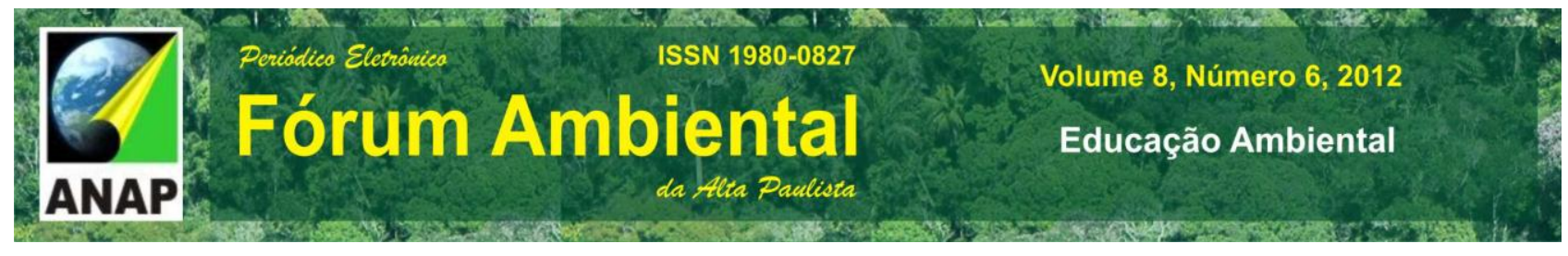

\section{REFERÊNCIAS}

AZEVEDO, L. P. D.; OLIVEIRA, E. L. D. Efeitos da aplicação de efluente de tratamento de esgoto na fertilidade do solo e produtividade de pepino sob irrigação subsuperficial. Engenharia Agrícola, v. 25, p. 253-263, 2005. ISSN 0100-6916. Disponível em: < http://www.scielo.br/scielo.php?script=sci_arttext\&pid=S0100-69162005000100028\&nrm=iso >.

BARRETO, A. C.; CAMPOS, C. M. M. Avaliação de um sistema de irrigação autopropelido aplicando água residuária de suinocultura. Ciência e Agrotecnologia, v. 33, p. 1752-1757, 2009. ISSN 1413-7054. Disponível em: < http://www.scielo.br/scielo.php?script=sci_arttext\&pid=S1413$70542009000700009 \&$ nrm $=$ iso $>$.

BRASIL. Ministério do Meio Ambiente. Conselho Nacional de Recursos Hídricos. Resolução №54, de 28 de novembro de 2005. Estabelece modalidades, diretrizes e critérios gerais para a prática de reuso direto não potável da água. Brasília, DF, 2005a.

BRASIL. Ministério do Meio Ambiente. Conselho Nacional do Meio Ambiente. Resolução №357, de 17 de março de 2005. Dispõe sobre a classificação dos corpos de água e diretrizes ambientais para o seu enquadramento, bem como estabelece as condições e padrões de lançamento de efluentes, e dá outras providências. Brasilia, DF, 2005b.

CARARO, D. C.; BOTREL, T. A. Uso de cloração e ar comprimido no controle do entupimento de gotejadores ocasionado pela aplicação de água residuária. Engenharia Agrícola, v. 27, p. 336345, 2007. ISSN 0100-6916. Disponível em: <

http://www.scielo.br/scielo.php?script=sci_arttext\&pid=S0100-69162007000300002\&nrm=iso >.

FLORENCIO, L. et al. Utilização de Esgotos Sanitários: Marcos Conceituais e Regulatórios. In: FLORENCIO, L. et al. Tratamento e Utilização de esgotos Sanitários. Rio de Janeiro: Abes, 2006. p. 1-16.

MEDEIROS, S. D. S. et al. Utilização de água residuária de origem doméstica na agricultura: estudo do estado nutricional do cafeeiro. Revista Brasileira de Engenharia Agrícola e Ambiental, v. 12, p. 109-115, 2008. ISSN 1415-4366. Disponível em: < http://www.scielo.br/scielo.php?script=sci_arttext\&pid=S1415-43662008000200001\&nrm=iso >.

NOBRE, R. G. et al. Produção do girassol sob diferentes lâminas com efluentes domésticos e adubação orgânica. Revista Brasileira de Engenharia Agrícola e Ambiental, v. 14, p. 747-754, 2010. ISSN 1415-4366. Disponível em: <

http://www.scielo.br/scielo.php?script=sci_arttext\&pid=S1415-43662010000700010\&nrm=iso >.

OLIVEIRA, R. A. et al. Influência da aplicação de águas residuárias de suinocultura na capacidade de infiltração de um solo Podzólico Vermelho-Amarelo. Revista Brasileira de Engenharia Agrícola e Ambiental, v. 4, p. 263-267, 2000. ISSN 1415-4366. Disponível em: < http://www.scielo.br/scielo.php?script=sci_arttext\&pid=S1415-43662000000200022\&nrm=iso >.

PATERNIANI, J. E. S. et al. Pré-filtração em pedregulho e filtração lenta com areia, manta não tecida e carvão ativado para polimento de efluentes domésticos tratados em leitos cultivados. Engenharia Agrícola, v. 31, p. 803-812, 2011. ISSN 0100-6916. Disponível em: < http://www.scielo.br/scielo.php?script=sci_arttext\&pid=S0100-69162011000400018\&nrm=iso >. 
SANDRI, D.; MATSURA, E. E.; TESTEZLAF, R. Desenvolvimento da alface Elisa em diferentes sistemas de irrigação com água residuária. Revista Brasileira de Engenharia Agrícola e Ambiental, v. 11, p. 17-29, 2007. ISSN 1415-4366. Disponível em: < http://www.scielo.br/scielo.php?script=sci_arttext\&pid=S1415-43662007000100003\&nrm=iso >.

SILVESTRE, M. E. D. Água doce no Brasil: razões de uma nova política. 2003. $134 f$.

Dissertação (Mestrado em Desenvolvimento e Meio Ambiente) - Universidade Federal do Ceará. Disponível em: <http://www.prodema.ufc.br/dissertacoes/077.pdf>.

SOUSA NETO, O. N. et al. Fertigação do algodoeiro utilizando efluente doméstico tratado.

Revista Brasileira de Engenharia Agrícola e Ambiental, v. 16, p. 200-208, 2012. ISSN 14154366. Disponível em: < http://www.scielo.br/scielo.php?script=sci_arttext\&pid=S1415$43662012000200011 \& \mathrm{nrm}=$ iso $>$.

TUNDISI, J. G. Água no século XXI: enfrentando a escassez. $2^{\circ}$ Ed. São Carlos, Rima, 2005, $248 p$.

VARALLO, A. C. T. et al. Alterações nos atributos de um Latossolo Vermelho-amarelo irrigado com água de reúso. Revista Brasileira de Engenharia Agrícola e Ambiental, v. 14, p. 372-377, 2010. ISSN 1415-4366. Disponível em: <

http://www.scielo.br/scielo.php?script=sci_arttext\&pid=S1415-43662010000400005\&nrm=iso >.

VARALLO, A. C. T.; SOUZA, C. F.; SANTORO, B. D. L. Mudanças nas características físicoquímicas de um latossolo vermelho-amarelo distrófico após a irrigação com água de reúso na cultura da alface-crespa (Lactuca sativa, L.). Engenharia Agrícola, v. 32, p. 271-279, 2012. ISSN 0100-6916. Disponível em: < http://www.scielo.br/scielo.php?script=sci_arttext\&pid=S0100$69162012000200007 \& n r m=i s o>$.

VIEIRA, D. B. As Técnicas de Irrigação. São Paulo: Globo, 1989. 263 p. 